\title{
Ground and satellite monitoring of atmospheric pollution processes in urban areas
}

\author{
Ruslana A. Amikishieva ${ }^{1,2}$, Vladimir F. Raputa ${ }^{1}$ and Anatoly A. Lezhenin ${ }^{1}$ \\ ${ }^{1}$ Institute of Computational Mathematics and Mathematical Geophysics SB RAS, Novosibirsk, Russia \\ ${ }^{2}$ Siberian Center FGBU "SRC "Planeta", Novosibirsk, Russia
}

\begin{abstract}
The results of the analysis of atmospheric pollution processes in the vicinity of the Chernorechensky cement plant and the Iskitim city were presented. Snow cover samples and high-resolution satellite images were used as research materials. The reconstruction of the fields of impurity concentration was carried out on the basis of low-parameter models. Statistical relationships were identified between ground-based and satellite observations.
\end{abstract}

\section{Keywords}

Atmosphere, pollution, monitoring, snow cover, NDSI, reconstruction model.

\section{Introduction}

The use of modern observation tools and mathematical modeling makes it possible to obtain a picture of the processes of pollutants transport in the atmosphere, areas of pollution, to assess the total aerosol fallout $[1,2,3,4]$. Snow cover is the budgetary and informative material for conducting ground and satellite observations in Siberia [3, 5, 6, 7, 8]. It accumulates the multicomponent composition of pollutants and reflects the spatial dynamics of the spread of atmospheric emissions from sources. Due to the snow cover, winter satellite images provide a picture of aerosol deposition of impurities across the territories $[5,6,9,10,11,12]$. Lowparameter models of mono- and polydisperse, in the case of low sources - light impurities can be used to reconstruct contamination fields. The features of the models (namely, the presence of aggregated parameters) make it possible to numerically reconstruct the concentration field with a limited set of ground-based observations $[3,13,14,15]$. The use of multispectral satellite images makes it possible to calculate the Normalized Difference Snow Index (NDSI), which indirectly characterizes the presence of impurities in the snow [16, 17]. The methods of statistical analysis reveal the presence of functional relationships between the data of ground measurements and the NDSI values. Joint use of terrestrial and satellite information allows better validation of modeling results and expands possible areas of research.

The aim of the work is a numerical analysis of the atmospheric pollution processes of urban and industrial territories of the Iskitim region on the data of ground and satellite monitoring of snow cover pollution.

SDM-2021: All-Russian conference, August 24-27, 2021, Novosibirsk, Russia

๑ruslana215w@mail.ru (R.A. Amikishieva); raputa@sscc.ru (V.F. Raputa); lezhenin@ommfao.sscc.ru

(A. A. Lezhenin)

(c) (1) $\odot 2021$ Copyright for this paper by its authors. Use permitted under Creative Commons License Attribution 4.0 International (CC BY 4.0).

CEUR Workshop Proceedings (CEUR-WS.org) 


\section{Research objects}

Environmental monitoring is a very important task for the majority of large cities [18, 19]. Air emissions from industrial enterprises have a negative impact on the health of the population and the ecosystems of the surrounding areas. Control over the state of the atmosphere of cities is carried out using both observation posts and natural tablets $[5,19]$.

The object of this study was the territory of Iskitim, one of the industrial centers of the Novosibirsk region. Iskitim is located $50 \mathrm{~km}$ south of Novosibirsk along the Berd River. The main part of the city is located in the valley of the Berd river. In this area, southern, southwestern winds prevail. The river valley has a significant impact on the processes of the spread of impurities from industrial enterprises, vehicles. Industrial enterprises such as a cement plant, a thermal power plant, a plant of reinforced concrete products, etc. are located directly within the city.

Particular attention is paid to the study of pollution in the vicinity of the Chernorechensk cement plant (CCP), which is located in the northern part of Iskitim. The structure of the plant's emissions is dominated by suspended solids, oxides of nitrogen and sulfur, benz(a)pyrene. The dispersed composition of dust emissions is characterized by significant heterogeneity [3].

\section{Models and methods}

The studies used ground-based monitoring data for the winter period of 2019-20, as well as high-resolution satellite images from the Sentinel-2A, $-2 \mathrm{~B}$ and Landsat- 8 spacecraft. The numerical reconstruction of the fields of atmospheric pollution was carried out according to low-parameter models: mono-, polydisperse. Linear correlation analysis methods were used to search for functional relationships between the amount of foreign impurities in snow samples and the value of the snow index (NDSI) calculated from satellite data. The capabilities of the developed geographic information system (GIS) were used to graphically represent the results of numerical modeling [15].

Mono- (1) and polydisperse (2) models for the numerical reconstruction of the fields of impurity concentration over a long period of time from point sources are presented in the form of formulas [13, 20, 21]:

$$
\begin{gathered}
Q_{m}(r, \phi, \vec{\theta})=\theta_{1} r^{\theta_{2}} \exp \left(\frac{-2 r_{m}}{r}\right) P\left(\phi+180^{\circ}\right), \\
Q_{p}(r, \phi, \vec{\theta})=\theta_{1} r^{\theta_{2}} \exp \left(\frac{\theta_{3}}{r}\right) P\left(\phi+180^{\circ}\right) .
\end{gathered}
$$

Here $r$ - the current distance from the emission source to the concentration measurement point, $r_{m}$ - the distance from the source where the maximum concentration of the impurity is observed, $\vec{\theta}$ - the vector of approximated parameters depending on the characteristics of the source and standard meteorological conditions, $P(\phi)$ - the wind rose.

The NDSI was used to assess the state of pollution of the snow cover. It is used for detecting snow cover and is the normalized difference between the visible green channel $(0.5-0.6 \mu \mathrm{m})$ and the shortwave infrared channel $(1.5-1.8 \mu \mathrm{m})[16,17]$. 
Numerical data processing was carried out using GIS functions. They allow processing multispectral satellite images, interpolating the contamination field based on NDSI values at reference points, and reconstructing the field of contamination from a point source based on ground-based observations.

\section{Results}

A numerical analysis of the studies of pollution of the snow cover processes was carried out separately for urban areas and the industrial zone of a cement plant. The city has a large number of sources of pollutant emissions, which does not allow directly applying the reconstruction models (1), (2). In the case of a cement plant, these models are quite appropriate.

\subsection{Territory of the Iskitim city}

In March 2020, snow sampling was carried out taking into account the dominant wind directions, relief and location of sources in the city. The selection scheme is shown in Figure 1 (leftmost fragment). Determination of the content of solid sediment in snow samples was carried out at the Institute of Inorganic Chemistry SB RAS.
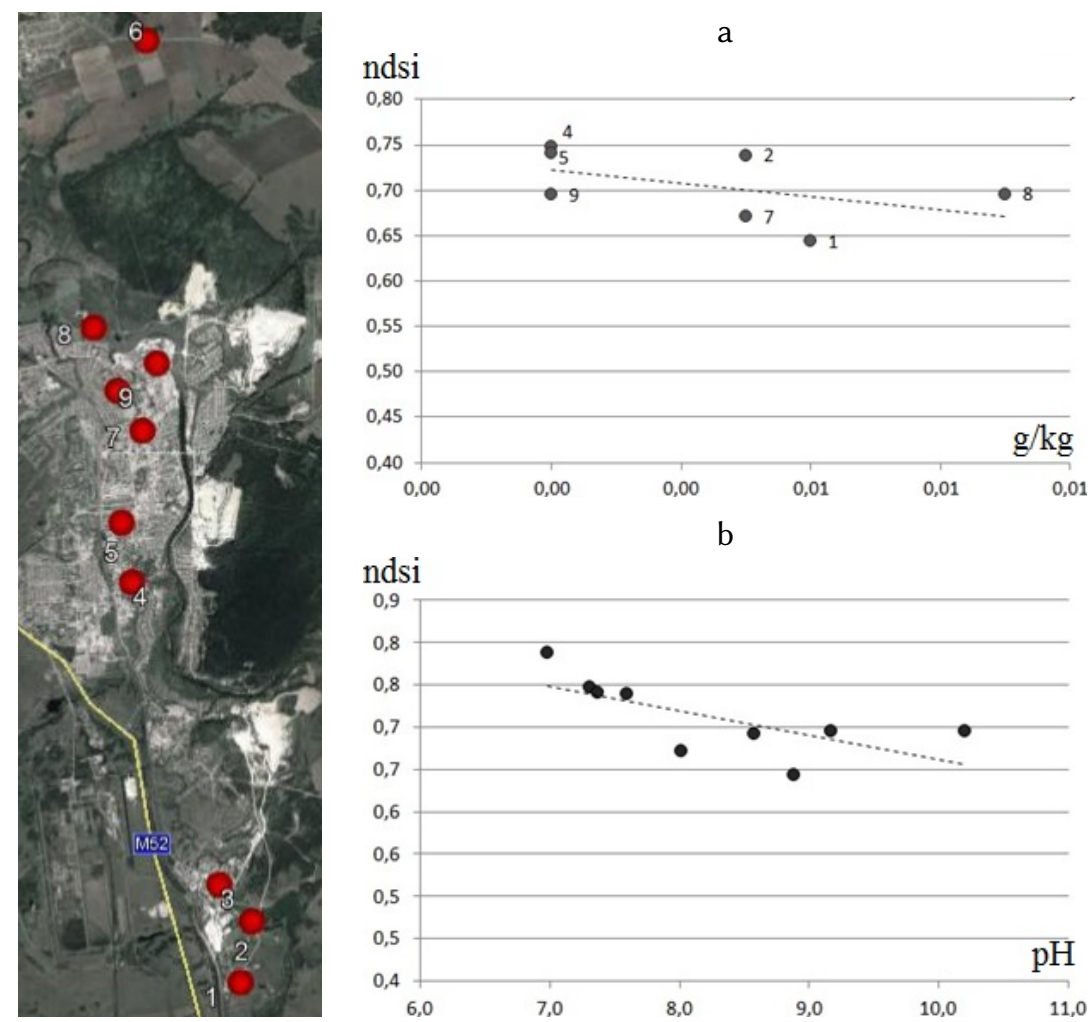

Figure 1: Sampling scheme in the territory of Iskitim, March 2020 correlation of NDSI values and measured impurity concentration (a); correlation of NDSI and $\mathrm{pH}$ values (b). 
The image from the Sentinel-2A spacecraft dated March 11, 2020, suitable in terms of date and quality, was selected to calculate the snow index.

Graphs of correlations between the values of the snow index and the physicochemical characteristics of the snow samples composition are shown in Figure 1. Calculations were made for the total concentration of impurities in the snow and for $\mathrm{pH}$ values (Figure 1, a, and b, respectively). Taking into account the measurement error and the relatively small resolution of the satellite image (20 m/pixel), we can observe consistency in the dynamics of changes in the reflectivity of the snow cover and the qualitative composition of impurities in it.

\subsection{The Chernorechensk cement plant}

In the vicinity of the plant in early March 2020, ground monitoring was carried out along several routes, taking into account the direction of the main removal of the admixture and the winter wind rose [22]. The sampling scheme for 2020 is shown in Figure 2, the rhombus marks the main sources of the plant - two closely spaced 80 meter pipes.

Northwestward from the source, sediment concentrations were calculated using a monodisperse reconstruction model (MMR) using two reference points at a distance of 0.72 and $1.64 \mathrm{~km}$ from CCP. The remaining nine points of ground measurements were used to control the quality of the numerical reconstruction. The result is shown in the graph (Figure 3, a and b) shows the correlation of NDSI values with the concentration of impurities in the samples.

The conditions allowed for a more detailed chemical analysis of snow samples in 2019. In particular, the concentrations of dissolved calcium $\left(\mathrm{Ca}^{2+}\right)$ and potassium $\left(\mathrm{K}^{+}\right)$, the compounds of which constitute the main removal of impurities from the cement plant, were calculated separately. The dependences of the dynamics of changes in the concentrations of $\mathrm{Ca}^{2+}, \mathrm{K}^{+}$and the characteristics of the degree of reflection of the snow cover are shown in the Figure 4, a and $b$. In both cases, a fairly high correlation coefficient is observed. To calculate the NDSI, an image from the Landsat-8 spacecraft from February 25, 2019 was selected.

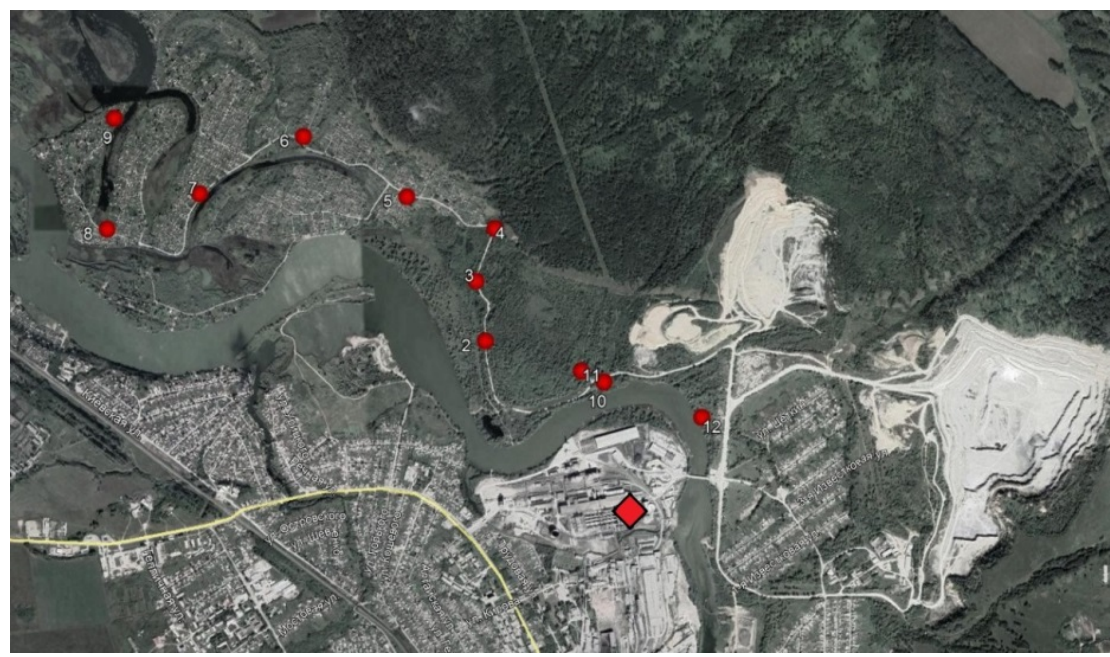

Figure 2: Snow sampling scheme in the vicinity Chernorechensk cement plant, 2020. 

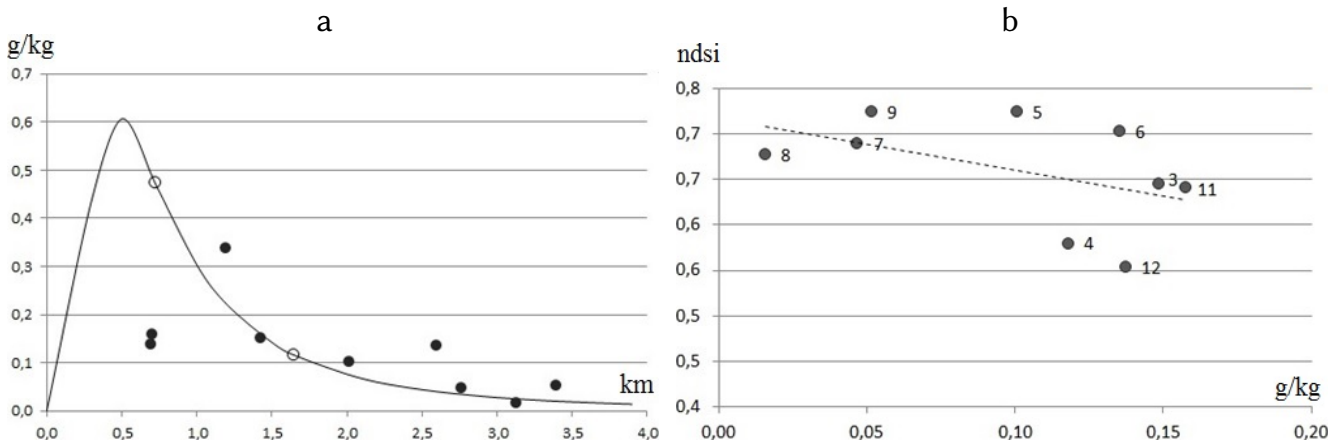

Figure 3: Graph of measured and calculated by MMR data impurity concentration (a); correlation of NDSI values and measured sediment concentration (b).
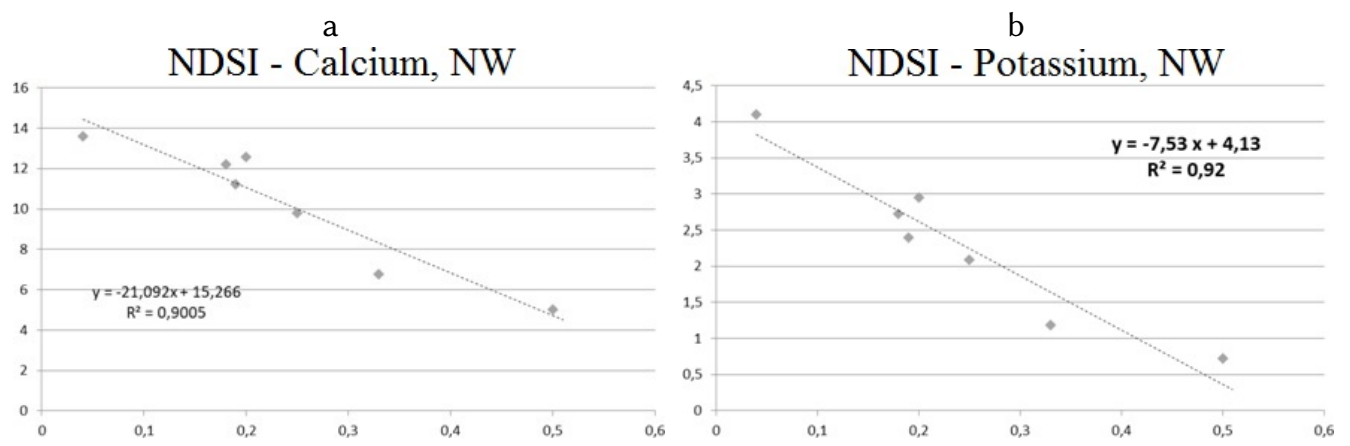

Figure 4: Correlation of snow index values and dissolved calcium (a), potassium (b).

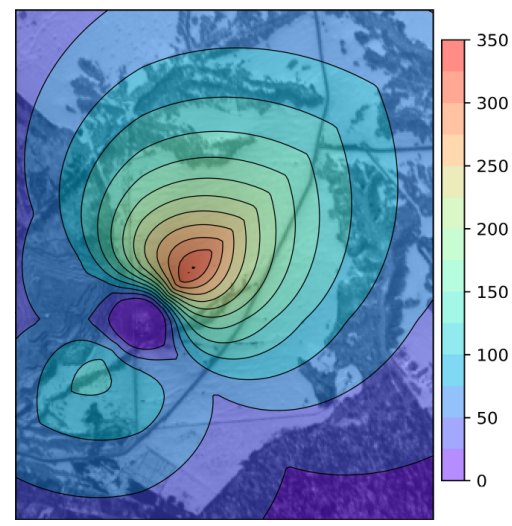

Figure 5: Reconstructed contamination field according to the polydisperse model.

Also, based on the values of the snow index, using GIS-systems, the fields of atmospheric pollution in the vicinity of the dry cement production workshop were reconstructed using MMR and PMR (Figure 5). This workshop is a relatively small source located $3 \mathrm{~km}$ east of CCP. The removal of suspended solids from the enterprise takes place on an open, flat area and is well fixed on the snow cover. 
Analysis of Figure 5 indicates that the main precipitation of suspended solids occurred in the northeast direction. The maximum concentration is located a few hundred meters from the industrial site of the dry cement production workshop.

\section{Conclusion}

Based on the data of ground and satellite monitoring of the snow cover, a numerical analysis of the pollution of the territory of Iskitim city and the environs of the Chernorechensk cement plant was carried out. Linear correlations between the solid sediment of snow samples, $\mathrm{pH}$ and the NDSI index at the sampling points were established for the territories of the city.

Reconstruction of the fields of precipitation of suspended solids in the zone of influence of atmospheric emissions from the Chernorechensk cement plant was carried out on the basis of low-parameter models. The functional relationships between the dissolved calcium, potassium and the NDSI index were established along the sampling route northwest of the cement plant pipes.

Joint use of ground and satellite information can significantly reduce the cost of monitoring studies of pollution of territories. The involvement of model descriptions of the processes of transfer of impurities from sources makes it possible to carry out the numerical reconstruction of pollution fields from a small number of observation points.

\section{Acknowledgments}

The work was carried out within the framework of the State Assignment for the ICM\&MG SB RAS (project 0215-2021-0003), with the financial support of the Russian Foundation for Basic Research and the Government of the Novosibirsk Region (project No. 19-47-540008).

\section{References}

[1] Berlyand M.E. Modern problems of atmospheric diffusion and atmospheric pollution. Leningrad: Gidrometeoizdat, 1975.

[2] Sedunov Yu.S., Borzilov V.A., Klepikova N.V. Physical and mathematical modeling of regional transport of radioactive substances in the atmosphere as a result of the accident at the Chernobyl nuclear power plant // Meteorology and Hydrology. 1989. No. 9. P. 5-10.

[3] Shcherbatov A.F., Raputa V.F., Turbinsky V.V., Yaroslavtseva T.V. Assessment of air pollution with dust based on snow survey data based on reconstruction of fallout fields // Health Risk Analysis. 2014. No. 2. P. 42-47.

[4] Balter B.M., Balter D.B., Egorov V.V., Stalnaya M.V. Using Landsat satellites data to determine the concentration of pollutants in plumes from blowing gas wells based on a source model // Earth Research from Space. 2014. No. 2. P. 55-66.

[5] Vasilenko V.N., Nazarov I.M., Fridman Sh.D. Monitoring of snow cover pollution. Leningrad: Gidrometioizdat, 1985.

[6] Prokacheva V.G., Usachev V.F. Snow cover as an indicator of cumulative pollution in 
the sphere of influence of cities and roads // Meteorology and Hydrology. 2013. No. 3. P. 94-106.

[7] Zhuravleva N.V., Potokina R.R., Ismagilov Z.R., Khabibulina E.R. Pollution of the snow cover with polycyclic aromatic hydrocarbons and toxic elements on the example of Novokuznetsk city // Chemistry for sustainable development. 2014. Vol. 22. No. 5. P. 445-454.

[8] Koroleva G.P., Gorshkov A.G., Vinogradova T.P. Investigation of snow cover pollution as a depositing environment (Southern Baikal region) // Chemistry for Sustainable Development. 1998. Vol. 6. P. 327-337.

[9] Dmitriev A.V., Dmitriev V.V. Tracking the correlation of NDVI dynamics in comparison with the aerosol fallout zone // Modern problems of remote sensing of the Earth from space. 2008. Vol. 1. No. 5. P. 92-95.

[10] Dmitriev A.V., Dmitriev V.V. Theoretical and experimental study of the melting process of snow cover in the region of Omsk based on materials from 2007-2009 // Modern problems of remote sensing of the Earth from space. 2011. Vol. 8. No. 2. P. 34-41.

[11] Vasilevich M.I., Shchanov V.M., Vasilevich R.S. Application of satellite research methods in assessing snow pollution around industrial enterprises in the tundra zone // Modern problems of remote sensing of the Earth from space. 2015. Vol. 12. No. 2. P. 50-60.

[12] Krutskikh N.V., Kravchenko I.Yu. Using Landsat satellite images for geoecological monitoring of urbanized territories // Modern problems of remote sensing of the Earth from space. 2018. Vol. 15. No. 2. P. 159-168.

[13] Bortnikova S.B., Raputa V.F., Devyatova A.Yu., Yudakhin F.N. Methods for analyzing data on snow cover pollution in the zones of influence of industrial enterprises // Geoecology. Engineering geology. Hydrogeology. Geocryology. 2009. No. 5. P. 447-457.

[14] Izrael Yu.A., Tsaturov Yu.S., Nazarov I.M. Reconstruction of the actual picture of radioactive contamination of the area as a result of accidents and nuclear tests // Meteorology and Hydrology. 1994. No. 8. P. 5-18.

[15] Amikishieva R.A., Raputa V.F., Yaroslavtseva T.V. Technologies for analyzing atmospheric pollution processes based on ground-based and satellite observations // Interexpo GEOSiberia. 2020. Vol. 4. No. 1. P. 36-41.

[16] Riggs G., Hall D., Salomonson V. A snow index for the Landsat thematic mapper and moderate resolution imaging spectrometer // Geoscience and Remote Sensing Symposium, IGARSS'94. Vol. 4: Surface and Atmospheric Remote Sensing: Technologies, Data Analysis, and Interpretation. 1994. P. 1942-1944.

[17] Hall D.K., Riggs G.A., Salomonson V.V., DiGirolamo N.E., Bayr K.J., Jin J.M. MODIS snowcover products // Remote Sensing of Environment. 2002. Vol. 83. No. 1. P. 181-194.

[18] Bezuglaya E.Yu., Smirnova I.V. Air of cities and its changes. St. Petersburg: Asterion, 2008.

[19] Bezuglaya E.Yu. Monitoring of the state of air pollution in cities. Leningrad: Gidrometeoizdat, 1986.

[20] Berlyand M.E., Genikhovich E.L., Kanchan Ya.S., Onikul R.I., Chicherin S.S. On the calculation of the average annual concentrations of impurities in the atmosphere from industrial sources // Proceedings of the GGO. 1979. No. 17. P. 3-18.

[21] Byzova N.L., Garger E.K., Ivanov V.N. Experimental studies of atmospheric diffusion and calculations of impurity scattering. Leningrad: Gidrometeoizdat, 1991.

[22] The climate of Novosibirsk. Leningrad: Gidrometeoizdat, 1979. 